\title{
Infants' routine video electroencephalogram findings in a Saudi tertiary hospital
}

\author{
Dalya A. Abualsaud, MD, Lamya A. Jad, MD, FRCPC.
}

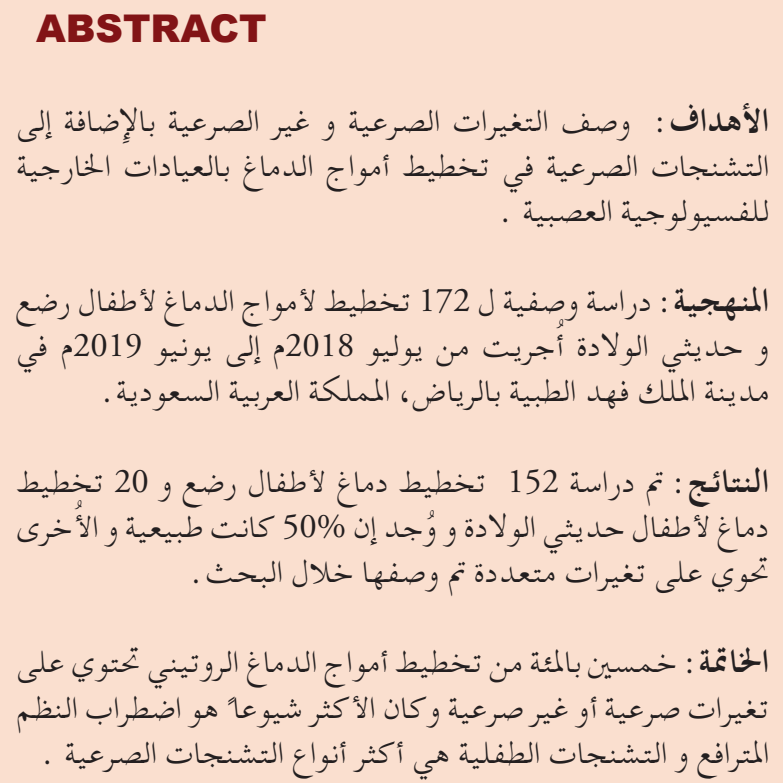

Objectives: To report the existence and describe the non-epileptic abnormalities, interictal epileptiform discharges, and seizures in routine electroencephalograms (EEGs) of infants in a tertiary hospital out-patient neurophysiology clinics.

Methods: : This is a non-interventional, retrospective descriptive study that involved the review of 172 infants' EEGs conducted from July 2018 to June 2019 in King Fahad Medical City, Riyadh, Kingdom of Saudi Arabia.

Results: Total of 172 EEGs were reviewed; 152 routine EEGs for infants and 20 neonatal EEGs. Seventy-six (50\%) EEGs were reported to be normal. Among the remaining EEGs, 54 were characterized by generalized slow background abnormalities (31.3 $\%$, seven (4\%) by background asymmetry, one $(0.5 \%)$ by generalized low amplitude, and one $(0.5$ $\%)$ by an alternate trace that was dysmature for age. Interictal epileptiform discharges (IED) were present in $75(43.6 \%)$ EEGs and they were focal in 72 $(41.8 \%)$ EEGs, and generalized spike wave discharges were seen in only 3 (1.7\%) EEGs with focal interictal epileptiform discharges. A diagnosis of hypsarrythmia was made from 15 (8.7\%) EEGs. There were seizures in $11(6.4 \%)$ EEGs, of which three were in neonates (15\% of neonatal EEGs), and 8 in infants ( $4.6 \%$ of infant EEGs).

Conclusions: Fifty \% of routine infants' EEGs had abnormalities and hypsarrythmia was the most common abnormal background associated with seizures. Ictal discharges in form of generalized electrodecremental pattern associated clinically with epileptic spasm was the most common type of seizures

Neurosciences 2020; Vol. 25 (5): 350-355 doi: 10.17712/nsj.2020.5.20200049

From the National Neuroscience Institute, King Fahad Medical City, Riyadh, Kingdom of Saudi Arabia.

Received 10th April 2020. Accepted 24th June 2020.

Address correspondence and reprint request to: Dr. Dalya A. Abualsaud, National Neuroscience Institute, King Fahad Medical City, Riyadh, Kingdom of Saudi Arabia. E-mail: drabualsaud@hotmail.com ORCID ID: https://orcid.org/0000-0002-5669-1475
$\mathrm{T}$ The incidence of neonatal seizures varies across countries, but is estimated to be between 1 to $3.5 / 1000(0.1-0.35 \%) .{ }^{1}$ These seizuresaremanifestations of neurological diseases in infants, and they are often the only symptom in a newborn with neurological dysfunction. In cases of neonatal and infantile seizures, neuroimaging is important for identifying the etiology of these events and as an additional diagnostic tool, which supplements the electroencephalogram (EEG) findings. In the process of evaluating the patient, either head ultrasonography (US), brain magnetic resonance (MRI), or head computed tomography (CT) is typically. For this article, we define an abnormal EEG as those including interictal epileptiform discharges or nonepileptiform abnormalities, or electrographic or clinical ictal patterns. This study reports the non-epileptic EEGs 
abnormalities, Interictal epileptiform discharges, and electrographic and clinical seizures in routine EEGs of neonates and infants up to 1-year-old in an out-patient neurophysiology clinic of a tertiary hospital, regardless of whether these patients were booked as out-patients or stable patients from an in-patient pediatric neurology ward. Patients undergoing portable EEGs outside the department were not included in the study.

Methods. We aimed to describe the abnormalities in the EEG of infants undergoing routine video EEGs in the neurophysiology department at a tertiary hospital.

This is a non-interventional, cross-sectional, retrospective descriptive study that involved the review of 172 infants' EEGs conducted over 12 months (July 2018 to June 2019)in the Neurophysiology Department of the King Fahad Medical City, Riyadh, Kingdom of Saudi Arabia.

In this study, the EEGs of pediatric patients $>365$ days old and portable EEGs outside the department were not included in the study. The EEGs were carried out using the 10-20 international placement system, and for neonatal EEG, a neonatal montage was used.

Routine EEGs of neonates and infants were in Neurophysiology Clinic, regardless of whether these patients are booked as out-patients or stable patients from the in-patient pediatric population. Portable EEGs outside the department were not included in the study.

If needed demographical data was collected and used in elaborating more about some specific diagnosis for example hypsarrythmia and seizures. Medical literature was reviewed through reviewing of related previously published studies. Ethical approval for this study was obtained from Institutional Review Board of the hospital.

Results. A total of 172 EEGs were reviewed: 152 routine EEGs for infants older than 1 month and 20 neonatal EEGs. Seventy-six (50\%) EEGs were reported to be within normal limits for age, but 23 of these normal EEGs had abnormal neuroimaging.

The remaining EEGs revealed generalized slow background abnormalities in 54 (31.3\%) EEGs, asymmetry in the background in 7 (4\%) EEGs, generalized low amplitude in one $(0.5 \%)$ EEG, and

Disclosure. Authors have no conflict of interests, and the work was not supported or funded by any drug company. trace alternate in one (0.5\%) EEG, which was dysmature for age. Interictal epileptiform discharges (IEDs) were present in 75 (43.6\%) EEGs, and they were focal in 72 (41.8\%) EEGs, and generalized spike-wave discharges were seen in only $3(1.7 \%)$ EEGs, in addition to focal Interictal epileptiform discharges. Furthermore, the diagnosis of hypsarrythmia was made in 15 EEGs, which was $8.7 \%$ of the total EEGs of which brain MRI results were abnormal in 6 (40\%), and 4 (26.6\%) patients were scheduled for brain MRI.

There were seizures (electrographic and/or clinical) in 11 EEGs (which represents 6.39\% the EEG recordings): 3 of these seizures were in neonates (which represents $15 \%$ of neonatal EEGs), and 8 seizures were in infants older than one month (which represents $4.6 \%$ of the infant EEGs).

There were 4 (36.3\%) electrographic and 7 (63.6\%) electroclinical seizures. Two $(66.67 \%)$ of 3 neonatal seizures were electrographic, and one was associated with clinical signs.

Regarding the semiology of seizures, 6 were generalized seizures in the form of clinical tonic spasms associated with EEG desynchronization what is called electrodecremental ictal pattern (Figure 1), and 5 seizures were focal seizures (Table1). In reviewing the chart of these patients, 2 had intensive care unit admission, and one was hospitalized. We reviewed the neuroimaging of all patients and found that 5 of 11 patients had abnormal neuroimaging (Table1). On magnetic resonance imaging (MRI), computed tomography (CT), or brain ultrasound, or a combination of these. Findings included 2 patients with bilateral symmetrical T2 hyperintensities involving the globuspallidi bilaterally and the lateral aspect of the thalamic nuclei. Three patients had diffuse cerebral atrophy. Four patients had a normal MRI brain, and 2 had unremarkable ultrasound (US) brain.

Discussion. This study examines the existence of epileptogenic and non-epileptogenic EEG abnormalities in infants undergoing routine video EEGs in a tertiary hospital in Saudi Arabia, where the prevalence rate (PR) for active epilepsy was $6.54 / 1000$ population (95\% confidence interval, 5.48-7.60), ${ }^{2}$ and the PR per 1000 population for neurological morbidity was 120.5 , including seizures (PR, 10.2), which was the second in incidence after headaches. ${ }^{3}$ Regrettably, there was no information regarding the prevalence or incidence of epilepsy or seizures in the pediatric age group in Saudi Arabia.

Among the 75 (43.6\%) EEGs that had interictal epileptiform discharges (IEDs), a history of epilepsy was 


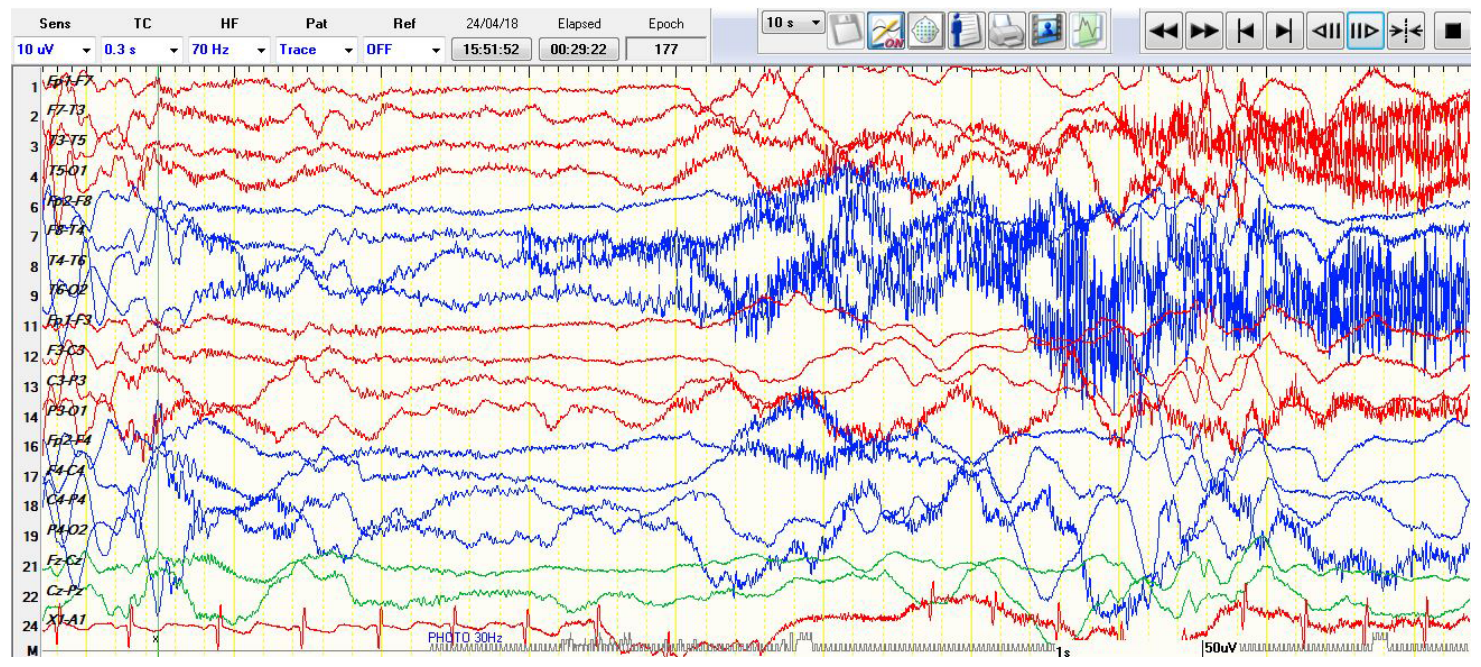

Figure 1 - Desynchronization (generalized electrodecremental ictal pattern) associated with epileptic spam.

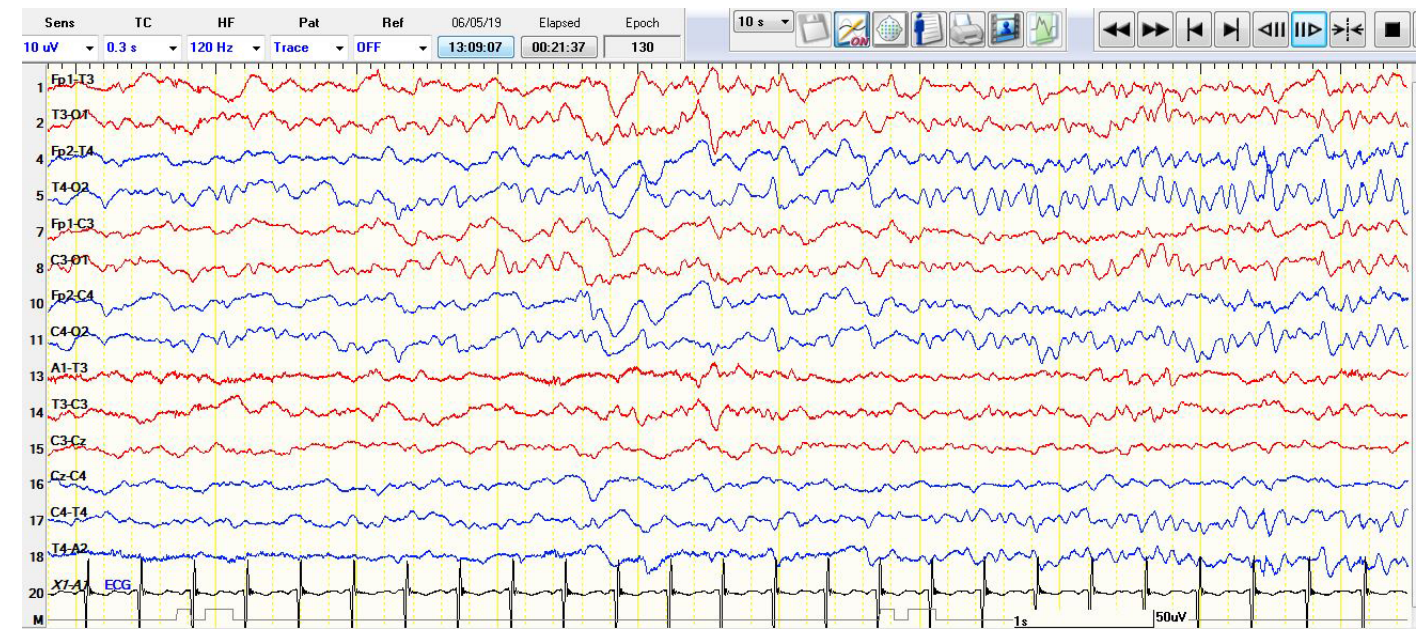

Figure 2 - There is a new rhythm medium amplitude alpha frequency $9 \mathrm{~Hz}$ arising from right temporal $\mathrm{T} 4$ with evolution to higher amplitude and slower in frequencies which is representing an ictal discharge.

present in $51(70.8 \%)$. Though the EEG has variable specificity (78-98\%) for epilepsy and a lesser sensitivity (25-56\%) to diagnose epilepsy, ${ }^{4}$ the rest of EEGs with IED (29.2\%) were requested as screening methods for patients without a history of seizures, stereotypical events, or abnormal movements. These patients had either a genetic syndrome or other neurological signs, such as hypotonia or hypertonia.

Since our study only looked at out-patient/ stable inpatient EEGs physically carried out in the Neurophysiology Department, this did not include sick inpatients that most likely had portable EEGs. This would theoretically decrease the yield of EEG abnormalities.
Fifty-four EEGs revealed generalized slow background abnormalities. Asymmetry in the background was found in seven (4\%) EEGs and all lateralized to identifiable structural abnormalities in their MRI brain. This finding is consistent with the work of Pourmand, who found that $76 \%$ of 42 EEGs had generalized asymmetric slow with hemispheric suppression in amplitude lateralized to a cerebral abnormality. ${ }^{5}$

Interestingly, Marble Bone disease or AlbersSchonberg disease (osteopetrosis) was the diagnosis of one $(0.5 \%)$ of our patients with generalized low amplitude on EEG. This EEG was done as a screening 
Table 1 - Age, EEG and neuroimaging of patients with seizures ( IED= interictal discharges).

\begin{tabular}{|c|c|c|c|c|}
\hline Patients & Age & EEG background \&IED & Ictal discharges & Neuroimaging \\
\hline 1 & Neonate & Hypsarrhythmia with multifocal IED & $\begin{array}{c}\text { electrographic seizures seen over the left } \\
\text { frontocentral }\end{array}$ & Normal MRI brain \\
\hline 2 & 8 Months & $\begin{array}{l}\text { Normal for age background with } \\
\text { multifocal IED }\end{array}$ & $\begin{array}{l}\text { Generalized electrodecremental ( epileptic } \\
\text { spasm ) }\end{array}$ & Normal MRI brain \\
\hline 3 & Neonate & $\begin{array}{l}\text { Normal for age background with no } \\
\text { IED }\end{array}$ & $\begin{array}{c}\text { An electrographic event } 9 \mathrm{~Hz} \text { right temporal } \\
\text { T4 ( Figure 2) }\end{array}$ & Normal brain US \\
\hline 4 & 6 Months & Hypsarrhythmia with multifocal IED & $\begin{array}{l}\text { Generalized electrodecremental (epileptic } \\
\text { spasm ) }\end{array}$ & $\begin{array}{l}\text { MRI brain: bilateral symmetrical } \\
\text { T2 hyperintensity involving the } \\
\text { globuspallidi bilaterally and the lateral } \\
\text { thalamic nuclei }\end{array}$ \\
\hline 5 & 10 Months & $\begin{array}{l}\text { Generalized slow background with } \\
\text { Left temporal IED }\end{array}$ & $\begin{array}{l}\text { Three electrographic seizures were recorded } \\
\text { all focal arising from left hemisphere }\end{array}$ & MRI brain: Diffuse cerebral atrophy \\
\hline 6 & 3 Months & $\begin{array}{l}\text { Generalized voltage attenuation of } \\
\text { background with no IED }\end{array}$ & $\begin{array}{l}\text { Generalized electrodecremental (epileptic } \\
\text { spasm ) }\end{array}$ & $\begin{array}{l}\text { MRI brain: Interval progression of the } \\
\text { diffuse cerebral atrophy. }\end{array}$ \\
\hline 7 & 7 Months & Hypsarrhythmia with Multifocal IED & $\begin{array}{l}\text { Generalized electrodecremental (epileptic } \\
\text { spasm ) }\end{array}$ & $\begin{array}{l}\text { MRI brain: bilateral symmetrical T2 } \\
\text { hyperintensity involving the globus } \\
\text { pallidi bilaterally and the lateral } \\
\text { thalamic nuclei . }\end{array}$ \\
\hline 8 & 4 Months & $\begin{array}{l}\text { Normal for age background with Left } \\
\text { temporal IED }\end{array}$ & $\begin{array}{l}\text { Ictal discharges at left temporal region } \\
\text { associated with clinical bradycardia }\end{array}$ & Normal MRI brain \\
\hline 9 & 2 Months & $\begin{array}{l}\text { Normal for age background with } \\
\text { Bilateral temporal IED }\end{array}$ & $\begin{array}{l}\text { Build up sharp waves on left temporal region } \\
\text { mostly electrographic seizure }\end{array}$ & $\begin{array}{l}\text { CT head : brain atrophy and } \\
\text { craniosynostosis }\end{array}$ \\
\hline 10 & Neonate & $\begin{array}{l}\text { Normal for age background with } \\
\text { multifocal IED }\end{array}$ & $\begin{array}{l}\text { Generalized electrodecremental (epileptic } \\
\text { spasm) }\end{array}$ & Normal brain US \\
\hline 11 & 4 Months & $\begin{array}{c}\text { Hypsarrhythmia with Multifocal } \\
\text { IED }\end{array}$ & $\begin{array}{c}\text { Generalized electrodecremental (epileptic } \\
\text { spasm) }\end{array}$ & Normal MRI brain \\
\hline
\end{tabular}

Table 2 - Demographic data of EEGs with seizures.

\begin{tabular}{lrl}
\hline EEG data & $\mathrm{n}$ & $(\%)$ \\
\hline Seizures(Electrographic \&Electroclinical) & 11 & $(6.4)$ from total EEG \\
Electrographic seizures & 3 & $(36.3)$ \\
Electroclinical seizures & 8 & $(63.6)$ \\
History of ICU admission or hospitalization & 2 & $(18.2)$ \\
Abnormal neuroimaging & 5 & $(45.45)$ \\
Focal seizures & 5 & $(45.45)$ \\
Generalized seizures & 6 & $(45.45)$ \\
\hline
\end{tabular}

method to exclude epilepsy, although there were no clinical seizures, there was a suspicion of abnormal movements, and for that, an antiepileptic medication was started as the EEG had generalized very low amplitude (suppression), most likely due to thick bone. In the data, one (0.5\%) EEG had a trace alternate, which was dysmature for age. Dysmaturity is any discrepancy between gestational age and EEG gestational age. If the lag between the chronicle conceptional age and the suspected conceptional EEG age is less than 2 weeks, this points to a short-lived central nervous system (CNS) dysfunction, but if it is more than 3 weeks, it specifies a higher probability of CNS persistence dysfunction. The maturation in neonatal EEG correlates with gestational age in amplitude, frequency, continuity, or discontinuity of background and changing in inter-burst intervals. ${ }^{6}$

Hypsarrhythmia, which is a continuous, high amplitude, asynchronous delta activities with interspersed independent multifocal spikes, $^{7}$ (Figure 3 ), was included in this study under both the slow background and presence of IED. To summarize, 15 EEGs were characterized by hypsarrythmia, accounting for $8.7 \%$ of total EEGs, and radiological imaging was reported to be abnormal in $6(40 \%$ of those with hypsarrythmia). Also, 4 (26.6\%) patients have appointments for brain MRI to be carried out later.

It is well known that structural abnormalities are found in almost two-thirds of patients with hypsarrhythmia/West syndrome, and some of these have genetic or metabolic diseases. ${ }^{8}$ Although the literature reports no predilection for gender, ${ }^{8}$ the hypsarrythmia was diagnosed in only three male infants but in 12 female infants.

Khreisat ${ }^{9}$ studied infantile spasm in 50 Jordanian children, which is a population reminiscent of the ethnic descent of Saudi population. The onset of infantile spasm occurred between 1 to 18 months old. The majority of their patients were male (74\%), which 


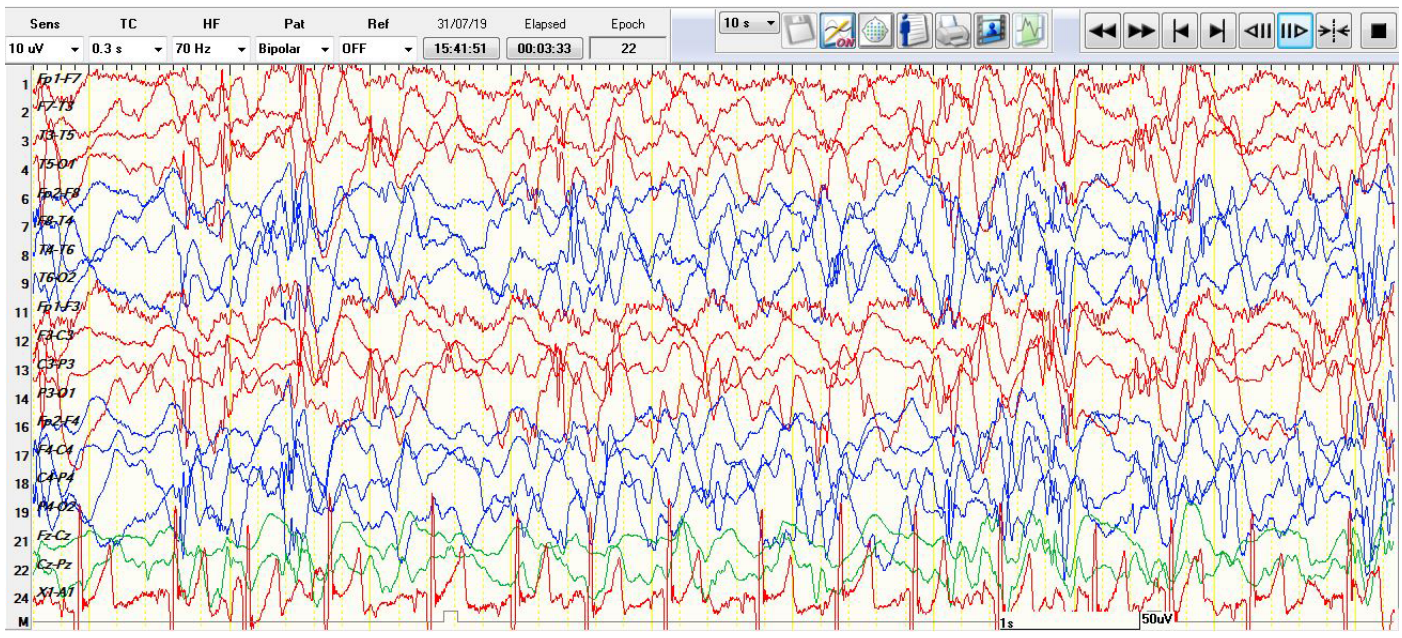

Figure 3 - Hypsarrhythmia, which is a continuous, high amplitude, asynchronous delta activities with interspersed independent multifocal spikes

is in contrast to our patients group. In the clinical presentation, flexor spasms $(52 \%)$ were the most common semiology in our patients.

In a Saudi study, Alrifai ${ }^{10}$ found that one of the common causes of infantile spasms is hereditary neurometabolic disorders in $10(12.5 \%)$ of 80 patients. There was a tendency toward poorer outcomes in the hereditary neurometabolic disorder individuals; nonetheless, there were no substantial differences in a clinical picture or radiological imaging.

Al-Sulaiman ${ }^{11}$ studied the clinical pattern and EEG abnormalities in 263 children between 6 months and 13 years old. Epileptiform activity was present in 50.6\%, which was generalized in $30.4 \%$, slow-wave activity in $15.6 \%$, and hypsarrhythmia in $1.1 \%$. The CT heads were normal in 60.5\%). Our study showed higher percentage of Hypsarrhythmia which was representing $8.7 \%$ of our EEGs, and abnormal radiological imaging in $40 \%$ and 26.6 had pending MRI brain and this difference in Hypsarrhythmia percentage most likely due to the difference in age group ranges as Al-Sulaiman`s study included EEGs of children up to age of 13 years old while this study only included infantile EEGs.

The total incidence of seizures (electrographic and clinical seizures) in infants and neonates was 6.4 $\%$. In more detail, seizures were found in $15 \%$ of all neonatal EEGs and $4.6 \%$ of infantile EEG in patients older than 1 month. These findings are compatible with a previous studies of out-patient routine EEG though the age group of their patients was wider, 7 of 46 records (15.2\%) revealed seizures (Liporace et al.,
1998 $)^{21}$ and, as described by Tatum et al, ${ }^{12}$ by reviewing 502 out-patient ambulatory EEG recordings, including patients between the age of 1 month to 93 years, the incidence of out-patient EEG seizures was $8.5 \%$, and $61.7 \%$ of these had electrographic seizures. ${ }^{12}$ These authors report that only $36.3 \%$ of these seizures were electrographic, with $63.6 \%$ being electroclinical, but the incidence of electrographic neonatal seizures was $66.67 \%$, which is similar to the findings of this study (Table 2).

In general, neonatal seizures might have ictal EEG activity as focal rhythmic discharge, lasting for longer than 10 seconds, and in regarding duration, the rhythmic ictal activity of fewer than $10 \mathrm{~s}$ is called brief ictal rhythmic discharges (BIRDs). Periodic lateralized epileptiform discharges (PLEDs) have sometimes been considered as electrical seizures. Generalized ictal rhythms are rare, and can be in the context of generalized myoclonus (generalized sharps) and spasms (generalized attenuation or electrodecrement). ${ }^{6}$

Prior intensive care unit (ICU) hospitalization was a risk factor for seizure in two $(18.2 \%)$ patients. ICU visit per say is a known risk factor for seizures ${ }^{13}$ although there is no clear relation that prior hospitalization is a risk factor for seizures.

One of our patients was admitted through an emergency for a cluster of seizures, and after stabilizing, he was sent to the neurophysiology department. His EEG revealed an electrographic seizure (or non-convulsiveseizures), though there were no clear periods of altered level of consciousness nor abnormal movements noticed by his family after stabilization, and 
it did not fulfill the epileptic status criteria as it had a short duration. The acute setting is a risk for nonconvulsive seizures (e.g., see the work by $\mathrm{Tu}^{14}$ ). Also, Miró et $\mathrm{al}^{15}$ found that $33 \%$ of emergencies have nonconvulsive status epilepticus (NCSE), and emergency EEG was performed to rule out NCSE and showed $92.1 \%$ sensitivity and $97.2 \%$ specificity.

Two (18.18\%) of our patients had MRI brain findings indicating metabolic diseases, and $3(27.27 \%)$ had cerebral atrophy. In general, abnormal MRI prevalence in infants with epilepsy is around $42.3 \%,{ }^{16}$ and data on the prevalence of neonatal seizures' neuroimaging is scarce but usually mentioned by etiologies in other studies. ${ }^{17}$

One of these patients had an extensive workup for his seizure disorder and developmental delay. His neurological examination revealed that, he was not fixating or following, he had axial and appendicular hypotonia with intact reflexes and upgoing planters, and was withdrawing to touch. A diagnosis of early infantile epileptic encephalopathy was confirmed based on whole-exome sequencing.

Abnormal neuroimaging was documented in radiological results of 23 (30.2\%) of 76 normal EEGs. This percentage is lower than a previous study done by Dr. Nilima Narkhede, ${ }^{18}$ which demonstrated that the EEG was not a good indicator of MRI result (as 50\% of abnormal MRIs of the brain had no abnormal EEG findings), and Coryell reported MRI abnormalities in $40 \%$ of epilepsy patients. ${ }^{19}$

In conclusion, half of routine EEGs of infants were containing abnormalities as abnormal background $(31.3 \%)$, presence of IED (43.6\%) or seizures $(6.4 \%)$. Hypsarrythmia was the most common abnormal background associated with seizures. Ictal discharges in form of generalized electrodecremental which was clinically associated with epileptic spasm was the most common type of seizures.

\section{References}

1. Saliba RM, Annegers JF, Waller DK, Tyson JE, Mizrahi E. M. Incidence of neonatal seizures in Harris County, Texas, 1992-1994. Am J Epidemiol 1999; 150: 763-769.

2. Al Rajeh S, Awada A, Bademosi O, Ogunniyi A. The prevalence of epilepsy and other seizure disorders in an Arab population: A community-based study. Seizure 2001; 10: 410-414.

3. Al-Rajeh S, Bademosi O, Awada A, Ismail H, Al-Freihi $\mathrm{H}$, Dawodu A, et al. Community survey of neurological disorders in Saudi Arabia: Results of thepilot study in Agrabiah. Ann Saudi Med 1995; 15: 32-35.

4. Smith SJM. EEG in the diagnosis, classification, and management of patients with epilepsy. J Neurol Neurosurg Psychiatry 2005; 76: 2-7.
5. Pourmand R. The significance of amplitude asymmetry in clinical electroencephalography. Clin Electroencephalogr 1994; 25: 76-80.

6. Nayak CS, Anilkumar AC, editors. Abnormal Neonatal EEG. In: StatPearls [Internet]. Treasure Island (FL): StatPearls Publishing; 2020 Jan.

7. Nayak CS, Anilkumar AC. Neonatal EEG. In: StatPearls [Internet]. Treasure Island (FL): StatPearls Publishing; 2019.

8. Xixis KL, Jain S. Infantile Spasm (West Syndrome). StatPearls Publishing; 2019.

9. Khreisat, W. Clinical profile of infants with hypsarrhythmia. ActaInformaticaMedica 2011; 19: 149-152.

10. Alrifai MT, Alshaya MA, Abulaban A, Alfadhel M. Hereditary neurometabolic causes of infantile spasms in 80 children presenting to a tertiary care center. Pediatric Neurology 2014; 51: 390-397.

11. Al-Sulaiman, AA, Ismail HM. Clinical pattern of newlydiagnosed seizures in Saudi Arabia: A prospective study of 263 children. Child's Nervous System 1999; 15: 468-471.

12. Tatum IV WO, Winters L, Gieron M, Passaro EA, Benbadis $S$, Ferreira J, et al. Outpatient seizure identification: results of 502 patients using computer-assisted ambulatory EEG. J Clin Neurophysiol 2001; 18: 14-9.

13. Jette N, Claassen J, Emerson RG, Hirsch LJ. Frequency and predictors of nonconvulsive seizures during continuous electroencephalographic monitoring in critically ill children. Arch Neurol 2006; 63: 1750-1755.

14. Tu TM, Loh NK, Tan NCK. Clinical risk factors for non-convulsive status epilepticus during emergent electroencephalogram. Seizure 2013; 22: 794-797.

15. Máñez Miró JU, Díaz de Terán, FJ, Alonso Singer P, AguilarAmat Prior MJ. Emergency electroencephalogram: Usefulness in the diagnosis of nonconvulsive status epilepticus by the on-call neurologist. Neurologia 2018; 33: 71-77.

16. Durá-Travé, T, Yoldi-Petri ME, Esparza-Estaún J, GallinasVictoriano F, Aguilera-Albesa S, Sagastibelza-Zabaleta A. Magnetic resonance imaging abnormalities in children with epilepsy. European Journal of Neurology 2012; 19: 1053-1059.

17. Weeke LC, Van Rooij LGM, Toet MC, Groenendaal F, De Vries LS. Neuroimaging in neonatal seizures. Epileptic Disord 2015; 17: 1-11.

18. Muona M, Fukata Y, Anttonen AK, Laari A, Palotie A, Pihko $\mathrm{H}$, et al. Dysfunctional ADAM22 implicated in progressive encephalopathy with cortical atrophy and epilepsy. Neurol Genet 2016; 2: e46.

19. Narkhede N, Maniar T, Kulkarni DS. Correlation clinical features with EEG finding and neuroimaging (MRI) abnormalities in children with seizure disorders. Journal of Dental and Medical Sciences 2017; 10: 1-4.

20. Jason Coryell, Gaillard WD, Shellhaas RA, Grinspan ZM, Wirrell EC, Knupp KG, et al. Neuroimaging of early life epilepsy. Pediatrics 2018; 142: e20180672.

21. Liporace J, Tatum W, Morris GL, French J. Clinical utility of sleep-deprived versus computer-assisted ambulatory 16-channel EEG in epilepsy patients: a multi-center study. Epilepsy Res 1998; 32: 357-362. 